
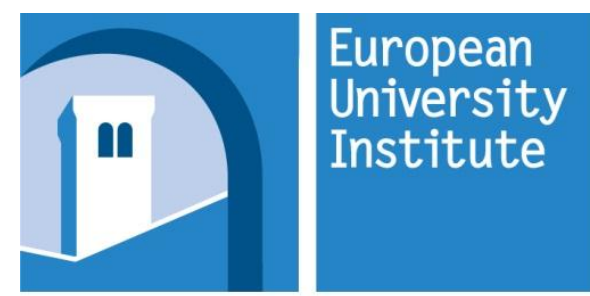

ROBERT

SCHUMAN

CENTRE FOR

ADVANCED

STUDIES

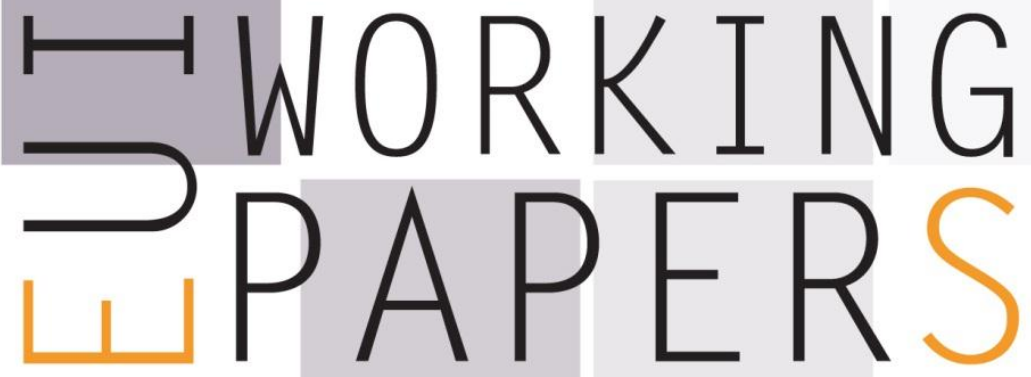

RSCAS 2013/52

Robert Schuman Centre for Advanced Studies Florence School of Regulation

Access regulation and the transition from copper to fiber networks in telecoms

Marc Bourreau, Carlo Cambini, Pınar Doğan 

European University Institute

Robert Schuman Centre for Advanced Studies

Florence School of Regulation

Access regulation and the transition from copper to fiber networks in telecoms

Marc Bourreau, Carlo Cambini, Pınar Doğan

EUI Working Paper RSCAS 2013/52 
This text may be downloaded only for personal research purposes. Additional reproduction for other purposes, whether in hard copies or electronically, requires the consent of the author(s), editor(s). If cited or quoted, reference should be made to the full name of the author(s), editor(s), the title, the working paper, or other series, the year and the publisher.

ISSN 1028-3625

(C) Marc Bourreau, Carlo Cambini, Pınar Doğan, 2013

Printed in Italy, July 2013

European University Institute

Badia Fiesolana

I - 50014 San Domenico di Fiesole (FI)

Italy

www.eui.eu/RSCAS/Publications/

www.eui.eu

cadmus.eui.eu 


\section{Robert Schuman Centre for Advanced Studies}

The Robert Schuman Centre for Advanced Studies (RSCAS), created in 1992 and directed by Stefano Bartolini since September 2006, aims to develop inter-disciplinary and comparative research and to promote work on the major issues facing the process of integration and European society.

The Centre is home to a large post-doctoral programme and hosts major research programmes and projects, and a range of working groups and ad hoc initiatives. The research agenda is organised around a set of core themes and is continuously evolving, reflecting the changing agenda of European integration and the expanding membership of the European Union.

Details of the research of the Centre can be found on:

http://www.eui.eu/RSCAS/Research/

Research publications take the form of Working Papers, Policy Papers, Distinguished Lectures and books. Most of these are also available on the RSCAS website:

http://www.eui.eu/RSCAS/Publications/

The EUI and the RSCAS are not responsible for the opinion expressed by the author(s).

\section{Florence School of Regulation}

The Florence School of Regulation (FSR) is a partnership between the Robert Schuman Centre for Advanced Studies (RSCAS) at the European University Institute (EUI), the Council of the European Energy Regulators (CEER) and the Independent Regulators Group (IRG). Moreover, as part of the EUI, the FSR works closely with the European Commission.

The objectives of the FSR are to promote informed discussions on key policy issues, through workshops and seminars, to provide state-of-the-art training for practitioners (from European Commission, National Regulators and private companies), to produce analytical and empirical researches about regulated sectors, to network, and to exchange documents and ideas.

At present, its scope is focused on the regulation of Energy (electricity and gas markets), of Communications \& Media, and of Transport.

This series of working papers aims at disseminating the work of scholars and practitioners on current regulatory issues.

\section{For further information}

Florence School of Regulation

Robert Schuman Centre for Advanced Studies

European University Institute

Via Boccaccio, 151

I-50133 Firenze

Tel.: +39055 4685751

Fax: +39055 4685755

E-mail: fsr@eui.eu

http://www.eui.eu/RSCAS/ProfessionalDevelopment/FSR/ 



\title{
Access regulation and the transition from copper to fiber
}

\author{
networks in telecoms*
}

\author{
Marc Bourreau† Carlo Cambini
}

June 11, 2013

\begin{abstract}
In this paper we study the impact of different forms of access obligations on firms' incentives to migrate from the legacy copper network to ultra-fast broadband infrastructures. We analyze three different kinds of regulatory interventions: geographical regulation of access to copper networks - where access prices are differentiated depending on whether or not an alternative fiber network has been deployed; access obligations on fiber networks and its interplay with wholesale copper prices; and, finally, a mandatory switch-off of the legacy copper network-to foster the transition to the higher quality fiber networks. Trading-off the different static and dynamic goals, the paper provides guidelines and suggestions for policy makers' decisions.
\end{abstract}

Keywords: Access pricing; Investment; Next generation networks.

JEL Codes: L96; L51.

\footnotetext{
${ }^{*}$ We thank participants at the 13th ACCC Regulatory Conference 2012 in Brisbane (AUS), and at the workshop "Public Intervention and Regulation" held in Capri (2012). Carlo Cambini acknowledges financial support from the Italian Ministry of Education (No. 20089PYFHY_004).

${ }^{\dagger}$ Telecom ParisTech, Department of Economics and Social Sciences, and CREST-LEI, Paris. Email: marc.bourreau@telecom-paristech.fr.

${ }^{\ddagger}$ Politecnico di Torino, Deparment of Management and Economics, \& EUI. Email: carlo.cambini@polito.it.

${ }^{\S}$ Harvard Kennedy School of Government, Harvard University. E-mail: pinar_dogan@hks.harvard.edu.
} 


\section{Introduction}

Investments in next-generation fiber networks have been focal to policy makers' attention, because the high-speed Internet services that rely on these networks are expected to have a significant impact on the society and the economy as a whole (Czernich et al., 2011). For example, in the European Union (EU), the European Commission (EC) has defined specific targets for the development of broadband services. ${ }^{1}$ However, recent data from the European Commission - DG Infosoc (2012) shows that these targets are at a far reach from the current status of broadband services in the EU, and therefore they can only be met if substantial infrastructure investments take place in the coming years. ${ }^{2}$

While policy makers aim at promoting investments in fiber networks, the regulatory tools that they use to achieve other ends, such static efficiency, can be detrimental for such infrastructure investments. In particular, it is often argued that setting too attractive terms of access to the legacy network to promote short-run competition can hinder entrant firms to invest in their own infrastructure and also reduce the infrastructure owners' incentives to maintain and upgrade their network. ${ }^{3}$ Infrastructure investments can be hindered not only by the current regulatory access policies, but also by the (perceived) future regulatory "threats," to the extent that they undermine the firms' expected returns from investment.

Fine tuning access policies to better address the tensions between different regulatory objectives is a challenging task, and the policy recommendations made so far by market specialists appear to be in sharp contrast with one another. For example, in a recent report for the European Competitive Telecommunication Association (ECTA), WIK (2011) proposes to decrease the access price to the

\footnotetext{
${ }^{1}$ More specifically, the EC has set $30 \mathrm{Mbps}$ as a minimum level of broadband connection that should be available to all EU citizens by 2013. As a longer term target, the EC has defined $100 \mathrm{Mbps}$ as the minimum level of broadband connection that at least half of the EU households should have access to by 2020 .

${ }^{2}$ Currently, $7.2 \%$ of all fixed lines provide speeds over $30 \mathrm{Mbps}$, and only $1.3 \%$ over $100 \mathrm{Mbps}$.

${ }^{3}$ See Cambini and Jiang (2009) for a recent and comprehensive survey on the relation between access regulation and investment.
} 
legacy (copper) networks to encourage incumbents to invest in new (fiber) networks, and to allow a rapid switch-off of the copper networks where fiber has already been installed. In contrast to WIK (2011)'s suggestion, in its report for the European (incumbent) Telecommunications Network Operators (ETNO), Plum (2011) states that a lower access price to the copper network would encourage customers to remain on copper, which would in turn discourage investments in nextgeneration access networks. ${ }^{4}$ In its recent report prepared for DG Information Society and Media, Haydock et al. (2012) from Charles River Associates argue that whether lower access prices to copper would trigger investment in fiber depends crucially on whether copper and fiber networks are operated in parallel. More specifically, they argue that lower access prices for copper would likely spur investment in fiber if copper is switched off at the time of fiber deployment, and that the effect of copper access prices on incentives to invest in fiber is ambiguous otherwise.

More often than not, copper and fiber networks do coexist, at least during a transitional phase of some length (i.e., when the copper network is not switched off immediately after the fiber deployment). By and large, the formal analysis on access pricing and investment by both incumbent and entrant firms considers settings in which the adoption of the new technology eliminates the old technology. ${ }^{5}$ Two notable recent exceptions are the studies by Inderst and Peitz (2012), and Bourreau, Cambini and Doğan (2012). ${ }^{6}$ Inderst and Peitz (2012) consider a setting in which both the legacy and the new infrastructure can coexist, and show that a higher access price to the legacy

\footnotetext{
${ }^{4}$ The potential impact of access policies in the transition from copper to fiber networks is acknowledged by the EC; see the EU Recommendation C(2010) 6223 on "Regulated Access to NGANs" (September 2010). In December 2012 the EC presented a new draft of recommendation stating that the access prices of the traditional copper networks should remain stable over the coming years in order to sustain investment in next-generation network by both incumbent and entrant firms (European Commission, 2012; paragraph 44 and 45).

${ }^{5}$ See for example, Gans and Williams (1999), Gans (2001), (2007), Foros (2004), Bourreau and Doğan (2005), (2006), Hori and Mizuno (2006), (2009), Kotakorpi (2006), Avenali et al. (2010), and Vareda and Hoernig (2010). These papers explore the impact of the access scheme on investment, when the investment decisions are "zero-one" in nature.

${ }^{6}$ See also Brito et al. (2012) who focus on the nature of innovation, which can be either drastic or non-drastic. Bourreau, Cambini and Hoernig (2012a) provide a review of the literature, with a particular focus on the process of migration from the legacy to the next generation infrastructures, and discuss the possibility of geographical access regulation. Bourreau, Lupi and Manenti (2013) study the migration from an old to a higher quality new technology when firms can offer services from both technologies.
} 
network lowers the incumbent's incentives to invest, while increasing that of the competing firm (who does not own a network at the beginning). The investment incentives of the entrants can be amplified even further if the incumbent and the entrants can sign contracts to fix the terms of usage of the new network.

While Inderst and Peitz (2012) consider network investment decisions in a single area (e.g., a country), Bourreau et al. (2012) consider different geographical areas within a country that differ with respect to the cost of rolling out the fiber network. They show that a higher access price to the legacy network fosters the entrant's firm investments, but that it has an ambiguous effect on the incumbent's investments due to two conflicting effects: the wholesale revenue effect, and the retail-level migration effect. A higher access price increases the incumbent's opportunity cost of investment due to the wholesale revenue effect (if the incumbent invests in a higher quality network, the entrant may invest in reaction, and the incumbent will then lose some wholesale profits). Furthermore, since the copper and fiber networks coexist, higher access prices (which imply high prices for the services provided with the copper network) also imply relatively high prices for the services provided with the fiber networks, increasing the returns from investing in fiber. This retail-level migration effect works in the opposite direction from that of the wholesale revenue effect, and hence, the net effect is ambiguous. Bourreau et al. show that the regulation of the access price to copper, alone, cannot overcome the tension between different regulatory objectives, namely, the promotion of static efficiency, fostering investments in new infrastructures, and avoiding unnecessary duplication of (fiber) networks.

While these studies shed light on how the access price to the legacy network may affect investment incentives for the transition from copper to fiber, this single access price turns out to be a rather limited tool, as the authors consider a single (uniform) price for access. Furthermore, these studies consider regulation of access only to the copper network. Regulatory requirements of access 
to fiber networks is not only a theoretical possibility, but is also hotly debated in several European countries. For example, in France, Germany, Italy, the UK and Spain, access to ducts and (less often) to dark fiber is mandated, while in other countries (such as the Netherlands and Germany) unbundling of fiber networks has been imposed (Cullen International, 2012).

In this paper we build on Bourreau et al. (2012) and address the following questions. First, can access price discrimination across different geographical areas resolve the tension between different regulatory objectives? This is an important question to address, as the latest EU Recommendation on fiber access points to geographically differentiated access remedies as one of the new approaches to be considered. ${ }^{7}$ We find that setting different access prices in different areas according to the fiber network roll-out improves regulatory outcomes, but it does not resolve the tension among different objectives entirely.

Second, when the fiber network is also subject to ex-ante access regulation, what is the (potential) interplay between the access prices for the copper and fiber networks? ${ }^{8}$ We find that regulators should not set the access prices to the two infrastructures independently, and that the sign of the correlation between the two prices should depend on which operator - the incumbent or the entrant - is expected to be the leader in fiber roll-out. When the incumbent has a larger fiber coverage than the entrant, the regulator should set an access price to the new infrastructure that is positively correlated with the access price to the legacy network, in order to incentivize both the entrant and the incumbent to invest. However, if the entrant has a larger fiber coverage than the incumbent, the regulator should set a low access price to copper (to level the playing field) in the uncovered areas and set a high access price on fiber to foster firms' investment incentives.

Finally, we extend our analysis to study the case in which the copper network is required to be

\footnotetext{
${ }^{7}$ Directive 2009/140/EC ("Better Regulation Directive", recital 7) explicitly considers the possibility of defining different geographical markets and remedies according to the prevailing competitive conditions.

${ }^{8}$ Bourreau et al. (2012) only briefly touches this question within a specified competitive setting.
} 
switched off upon the deployment of fiber, and show that this grants the regulator greater flexibility in setting the access price to fiber, because the copper switch-off obligation forces migration to fiber at the wholesale level.

The rest of the paper is organized as follows. In Section 2 we set up the model. In Section 3 we study a benchmark with no access to fiber. We also study the effect of an upgrade of the copper network on investment in fiber, and consider access price discrimination across different areas as an alternative regulatory tool to uniform pricing. In Section 4 we introduce ex-ante access regulation to the fiber network, and study the interplay between two access prices. We also consider a mandatory switch-off for the copper network. Finally, we conclude in Section 5.

\section{The setting}

We build on the model provided by Bourreau et al. (2012), and consider competition between an incumbent operator (firm 1) and an entrant operator (firm 2) in the broadband telecommunications market. At the beginning of the game, both firms rely on the incumbent's copper network to provide broadband services. The entrant leases access to the incumbent's copper network (e.g., through a local loop unbundling offer) at the regulated per-unit access price $a \geq 0 .{ }^{9}$ We assume that the marginal cost of providing access is constant and normalize it to 0 .

Both firms sequentially invest in fiber networks, and we assume that the incumbent makes its investment first. ${ }^{10}$ When a firm invests in a fiber network in a given area, it no longer employs the copper network to provide broadband services, that is, in that area the new technology replaces the old one for the firm in question. A firm can also ask for access to its rival's fiber infrastructure at the regulated per-unit access price $\widetilde{a} \geq 0$.

\footnotetext{
${ }^{9}$ The analysis provided by Bourreau et al. (2012), who do not consider regulation of the fiber network, constitutes our benchmark in this paper. We introduce access to fiber in Section 4.

${ }^{10}$ This sequence of moves reflects the idea that incumbent firms may have specific advantages in the deployment of the new infrastructure (due to their control over the existing infrastructure).
} 
Investment costs. We consider a country composed of a continuum of areas, with a total size of $\bar{z}$. The fixed cost of rolling out the fiber network varies in different areas of the country, and we order the areas (from 0 to $\bar{z}$ ) so that the ranking reflects the order of the magnitude of NGN investment costs (from low to high).

For each firm $i=1,2$, the decision to invest in fiber involves setting the areas $\left[0, z_{i}\right]$ in which its fiber network will be rolled out, with $\left[0, z_{i}\right] \subset[0, \bar{z}]$.

The fixed cost of covering an area at a given location $x \in[0, \bar{z}]$ is denoted by $c(x)$, with $c(x)>0$ and $c^{\prime}(x)>0$, and it is the same for both firms. The total cost of covering the area $\left[0, z_{i}\right]$ for firm $i$ is then $C\left(z_{i}\right)=\int_{0}^{z_{i}} c(x) d x$, and we have $C^{\prime}\left(z_{i}\right)=c\left(z_{i}\right)>0$ and $C^{\prime \prime}\left(z_{i}\right)=c^{\prime}\left(z_{i}\right)>0$.

Demand for broadband services. We use the competitive setting provided by Katz and Shapiro (1985). The indirect utility function of a consumer of type $\tau$ is $U=\tau+s_{i}-p_{i}$, where $s_{i}$ and $p_{i}$ denote the quality and price of firm $i$, with $i=1,2$. Consumers' types are uniformly distributed over $(-\infty, 1] .{ }^{11}$ Firms set quantities, and we normalize marginal costs to zero. We allow firms to set different quantities in different areas depending on their network technology and that of their rival. We use the superscripts " $O$ " and " $N$ " for the old (copper) and new (fiber) networks, respectively. The profit of firm $i=1,2$ in a given area, gross of investment cost, is denoted by $\pi_{i}^{k, l}$, where $k, l=O, N$ refer to the network technology of the incumbent and the entrant, respectively.

We denote by $s^{O}$ and $s^{N}$ the quality of the old copper network and new fiber network, respectively. We assume that $s^{N}>s^{O}$, and that $s^{N}<\left(1+5 s^{O}\right) / 4$, which ensures the coexistence of both networks in equilibrium (i.e., a firm using the copper network is not evicted by a firm using a fiber network), and that the quality difference is not so high that it would be socially efficient to close the low-quality network. Finally, we assume that the access prices to the copper and fiber

\footnotetext{
${ }^{11}$ Allowing for negative values of $\tau$ avoids corner solutions where all consumers purchase one of the two firms' services.
} 
networks are not too high so that an access seeker always makes a positive profit in any local area, gross of investment costs.

The timing. The timing of the game is as follows: The regulator sets the access price on the copper network, $a$, and on the fiber network, $\widetilde{a}$ (in the benchmark case we consider access to the copper network only). Then, the incumbent decides on the areas in which to roll-out a fiber network, $z_{1}$. Having observed the incumbent's decision, the entrant decides on its own fiber network coverage, $z_{2}$. Finally, firms compete in quantities.

\section{A benchmark: No access to fiber}

We start by studying a benchmark case, where there is no access to fiber. In any given geographical area, depending on the investment decisions of the firms for that area and on the access requirements set by the regulator, the competitive environment is defined by one of the three following configurations:

1. Service-based competition within the copper network. Both firms employ the incumbent's copper network to provide broadband services, and obtain gross profits $\pi_{i}^{O, O}$, for $i=1,2$.

2. Infrastructure-based competition between the copper and the fiber networks. This can happen under two different cases:

i. the incumbent uses its copper network, while the entrant employs its own fiber network; they obtain the gross profit $\pi_{i}^{O, N}$;

ii. the incumbent employs its fiber network, while the entrant relies on access to the incumbent's copper network, and they obtain the gross profit $\pi_{i}^{N, O}$. 
3. Infrastructure-based competition between the fiber networks. Both firms employ their own fiber network and obtain the gross profit $\pi_{i}^{N, N}$.

In our setting, since we limit the quality difference between the copper and fiber networks, configuration (2) is viable, i.e., the legacy and the new network can coexist in a given area. ${ }^{12}$

In what follows, we start by characterizing the equilibrium coverage as a function of the access price to the copper network. Then, we study the potential effects of a quality upgrade of the copper network on investments in fiber. Finally, we discuss the impact of a geographical differentiation of the access price to copper on social welfare.

\subsection{Equilibrium fiber coverage with no access to fiber}

The coverage game without access to fiber is studied in detail in Bourreau et al. (2012), therefore we just summarize and discuss here the different equilibria that can emerge in the sequential game.

The profits in the last stage of the game for each industry configuration (1) to (3) can be found in Appendix A. When the entrant relies on the incumbent's infrastructure to provide its services (i.e., in industry configurations (1) and (2.ii)), its profit decreases with the access price $a$, whereas the incumbent's profit increases with the access price up to the monopoly access price (which we denote by $\widehat{a}^{O}$ and $\widehat{a}^{N}$, when the incumbent uses the old and new technology, respectively). ${ }^{13}$ Finally, the incumbent makes more profit when the entrant leases access to the copper network (configurations (1) and (2.ii)) than when the entrant uses its own fiber network (configurations (2.i) and (3)). ${ }^{14}$

In the coverage game, given that the incumbent has covered a certain fraction of a country with fiber, the entrant decides to deploy its own fiber network up to the level that maximizes its total

\footnotetext{
${ }^{12}$ That is, for $i=1,2$, we have $\pi_{i}^{O, N}>0$, and $\pi_{i}^{N, O}(a)>0$ for $a$ not too high.

${ }^{13}$ See Appendix B1.

${ }^{14}$ See Appendix B2.
} 
profit. Assuming that the incumbent has covered the areas $\left[0, z_{1}\right]$, the entrant's profit is

$$
\Pi_{2}\left(z_{1}, z_{2}\right)=-C\left(z_{2}\right)+\left\{\begin{array}{ll}
z_{2} \pi_{2}^{N, N}+\left(z_{1}-z_{2}\right) \pi_{2}^{N, O}(a)+\left(\bar{z}-z_{1}\right) \pi_{2}^{O, O}(a) & \text { if } z_{2} \leq z_{1} \\
z_{1} \pi_{2}^{N, N}+\left(z_{2}-z_{1}\right) \pi_{2}^{O, N}+\left(\bar{z}-z_{2}\right) \pi_{2}^{O, O}(a) & \text { if } z_{2}>z_{1}
\end{array} .\right.
$$

The entrant may decide to invest more (i.e., to cover more areas) or less (i.e., to cover less areas) than the incumbent. The incumbent then reacts to the entrant's optimal investment decision by deciding on the coverage that maximizes its own profit in both scenarios. This sequential coverage game has two potential asymmetric interior equilibria. ${ }^{15}$ In the first asymmetric equilibrium, the entrant dominates the fiber market, that is, the entrant reaches a coverage, $z_{2}^{m}$, which is larger than the incumbent's coverage, $z_{1}^{c}$, with $z_{2}^{m}(a)=(c)^{-1}\left(\pi_{2}^{O, N}-\pi_{2}^{O, O}(a)\right)$ and $z_{1}^{c}=(c)^{-1}\left(\pi_{1}^{N, N}-\pi_{1}^{O, N}\right)$. In the second asymmetric equilibrium, the incumbent invests more in fiber coverage than the entrant and dominates the fiber market; the incumbent covers $z_{1}^{m}(a)=(c)^{-1}\left(\pi_{1}^{N, O}(a)-\pi_{1}^{O, O}(a)\right)$, whereas the entrant covers $z_{2}^{c}(a)=(c)^{-1}\left(\pi_{2}^{N, N}-\pi_{2}^{N, O}(a)\right)$, with $z_{1}^{m}>z_{2}^{c}$.

Bourreau et al. show in a more general setting that the global fiber coverage (which is the total coverage of the firm that has the largest fiber network coverage) can vary non-monotonically with the access price of the copper network. ${ }^{16}$ This result is due to the coexistence of three different effects: (i) the replacement effect that hinders infrastructure investment by alternative operators when the access price is low; (ii) the wholesale revenue effect that discourages the incumbent to invest in a higher quality network when the access price is low (since the entrant may invest in reaction, and the incumbent will then lose some of its wholesale profits); and finally (iii) the retaillevel migration effect: when the access price to the copper network is low, the retail prices of the services which rely on the copper network are also low. Therefore, in order to encourage customers

\footnotetext{
${ }^{15}$ There is also a potential asymmetric corner equilibrium. However, to simplify the exposition, we focus on the interior equilibria. Though there are multiple candidate equilibria, the equilibrium is always unique.

${ }^{16}$ See Proposition 1 in Bourreau et al. (2012).
} 
to switch from copper to fiber, operators should also offer low prices for fiber services. This effect reduces the profitability of the fiber infrastructure, and hence, the incentives to invest in it.

In our setting with a specific demand system, a higher access price leads locally to higher fiber investments as we have $\partial z_{1}^{m} / \partial a \geq 0, \partial z_{2}^{m} / \partial a \geq 0$, and $\partial z_{2}^{c} / \partial a \geq 0$, while $\partial z_{1}^{c} / \partial a=0 .{ }^{17}$ This rather intuitive finding is in line with most of the empirical evidence. For example, most recently, Distaso et al. (2009) found a positive correlation between access prices and the development of alternative broadband infrastructures. ${ }^{18}$

\subsection{Technological upgrade of the copper network}

Bourreau et al. (2012) assume that the quality difference between the old and the next generation networks is fixed. However, recent technologies such as "vectoring" can improve the speed of broadband connections provided on the copper network, and hence reduce the quality advantage of the fiber network. Since in many countries the deployment of the vectoring technology is subject to the regulator's authorization, it is interesting to study how the equilibrium investments in fiber coverage would be affected by an exogenous increase in the quality of the copper network, $s^{O}$. We have the following result for the two asymmetric equilibria.

Proposition 1 A higher quality of the copper network leads to lower investments in fiber coverage.

Proof. See Appendix C.

\footnotetext{
${ }^{17}$ This result is provided as an example by Bourreau et al. (2012) in Lemma 4.

${ }^{18}$ See also Christodoulou and Vlahous (2001), Crandall et al. (2004), Willig (2006), and Waverman et al. (2007). Christodoulou and Vlahous (2001) analyze the impact of unbundling rates in a simulated context with a mix of facilities and services competition, and find that increasing the access rates promotes investment by both historic operators and entrants. In a similar vein, using data on 15 European countries from 2002 to 2006, Crandall et al. (2004) find that access prices that are too low do not encourage new entrants to build their own facilities after gaining market experience. Willig (2006) finds that a small reduction (1\%) in unbundled network elements rates induces a more than proportional increase in the historic operator's investment (2.1\% to $2.9 \%$ ). Waverman et al. (2007) examine the impact of local loop unbundling prices on alternative infrastructures' market share, and find that a reduction in the local loop unbundling price causes a more than proportional reduction in the subscribers share of alternative infrastructures.
} 
In our setting, a quality upgrade of the copper network generates the following effects: $(i)$ the above mentioned replacement and wholesale revenue effects are intensified, as both the incumbent and the entrant make higher profits with the copper network, and (ii) the profitability of fiber is decreased, due to a lower quality advantage of fiber services over copper network services. Both of these effects lead to a reduction of investment incentives, and hence firms invest in less fiber coverage when the copper network is upgraded.

From a policy perspective, this result suggests that the regulator has to trade off between spurring high-speed broadband services via an upgrade of the copper network or the deployment of fiber infrastructures.

\subsection{Geographical differentiation of copper access prices}

As studied in Bourreau et al. (2012), when determining the access price to the legacy network, the regulator faces a standard trade-off between static efficiency and investment incentives, but also a trade-off between the social benefits of network expansion and the social costs of duplication. A single regulatory instrument (i.e., setting a uniform access price to the legacy network) is insufficient to overcome the tension between the - potentially conflicting - three regulatory objectives: $(i)$ achieving static efficiency in uncovered (or partially covered) areas, (ii) providing firms with appropriate investment incentives, and (iii) setting right the frontier between the areas with two competing fiber infrastructures and the areas with a monopoly fiber infrastructure (i.e., the appropriate level of infrastructure duplication).

One potential solution would be to allow the regulator to set different access prices for copper, ${ }^{19}$ depending on whether there is infrastructure competition between different technological (copper and fiber) networks. In our framework, this differentiation of access prices matters only when the

\footnotetext{
${ }^{19}$ Bourreau, Cambini and Hoernig (2012b) study geographical access rules that apply to the fiber network, without considering access to copper.
} 
incumbent dominates NGN investments, and we therefore focus on this case. ${ }^{20}$

Let $a^{O}$ and $a^{N}$ denote the access prices for the areas with no fiber network (i.e., configuration (1)) and with a single fiber network (i.e., configuration (2)), respectively. The expressions for social welfare in local areas are provided in Appendix D, where we also prove that $d w^{O, O} / d a^{O}<0$ and $d w^{N, O} / d a^{N}<0$. The coverage game with differentiated access prices is solved in Appendix E.

In what follows, we first determine the (local) social optimum in terms of coverage and access prices when the incumbent dominates fiber investments, and then study whether the regulator can implement the social optimum with differentiated access prices.

The social optimum when the incumbent dominates fiber investment. Assume that firm 1 and firm 2's coverage, $z_{1 w}$ and $z_{2 w}$, are set by the regulator, together with the differentiated access prices, $a_{w}^{O}$ and $a_{w}^{N}$, with $z_{1 w} \geq z_{2 w}$. The subscript " $w$ " stands for the welfare-maximizing solution. The social welfare is given by

$$
W=z_{2 w} w^{N, N}+\left(z_{1 w}-z_{2 w}\right) w^{N, O}\left(a_{w}^{N}\right)+\left(\bar{z}-z_{1 w}\right) w^{O, O}\left(a_{w}^{O}\right)-C\left(z_{1 w}\right)-C\left(z_{2 w}\right) .
$$

Assuming an interior solution, the local social optimum is then obtained when ${ }^{21}$

$$
\begin{gathered}
\frac{\partial W}{\partial a_{w}^{O}}=\frac{d w^{O, O}}{d a_{w}^{O}}=0, \\
\frac{\partial W}{\partial a_{w}^{N}}=\frac{d w^{N, O}}{d a_{w}^{N}}=0,
\end{gathered}
$$

\footnotetext{
${ }^{20}$ When the entrant dominates NGN investments, it leases access to the copper network only in the areas where the incumbent also uses the copper technology. There is therefore no room for differentiation of the access price. See also Appendix E where we determine the coverage equilibrium, and show that when the entrant dominates, coverage depends only on the access charge in uncovered areas.

${ }^{21}$ We focus on the configuration where the incumbent invests more in fiber than the entrant. Note however that the "global" social optimum can be achieved with a configuration where the incumbent does not dominate NGN investment.
} 


$$
\frac{\partial W}{\partial z_{1 w}}=w^{N, O}\left(a_{w}^{N}\right)-w^{O, O}\left(a_{w}^{O}\right)-c\left(z_{1 w}\right)=0
$$

and

$$
\frac{\partial W}{\partial z_{2 w}}=w^{N, N}-w^{N, O}\left(a_{w}^{N}\right)-c\left(z_{2 w}\right)=0
$$

Equations (1) and (2) state that the access prices $a_{w}^{O}$ and $a_{w}^{N}$ should be set so as to maximize local welfare in areas of type (1) and (2ii), respectively. Since $d w^{O, O} / d a^{O}<0$ and $d w^{N, O} / d a^{N}<0$, and since we have assumed positive access prices, this is achieved when $a_{w}^{O}=0$ and $a_{w}^{N}=0$ (access prices are bounded at zero, which represents the marginal cost due to our normalization).

Equation (3) states that the total fiber coverage, $z_{1 w}$, should be set such that welfare in areas with a single fiber infrastructure equates the cost of building this infrastructure plus the opportunity social cost (i.e., local welfare with service-based competition on copper).

Finally, equation (4) means that the coverage of the small network, $z_{2 w}$, should be set such that the welfare gain of having competition between fiber infrastructures instead of a single fiber infrastructure equates the cost of duplicating infrastructure.

Can differentiated access prices achieve the social optimum? We now determine whether the regulator can implement the social optimum defined above with differentiated access prices, when fiber coverage is determined by the market outcome. In this case, for given access prices $a^{O}$ and $a^{N}$, the social welfare is

$$
\begin{aligned}
W= & z_{2}^{c}\left(a^{N}\right) w^{N, N}+\left(z_{1}^{m}\left(a^{O}, a^{N}\right)-z_{2}^{c}\left(a^{N}\right)\right) w^{N, O}\left(a^{N}\right)+\left(\bar{z}-z_{1}^{m}\left(a^{O}, a^{N}\right)\right) w^{O, O}\left(a^{O}\right) \\
& -C\left(z_{1}^{m}\left(a^{O}, a^{N}\right)\right)-C\left(z_{2}^{c}\left(a^{N}\right)\right) .
\end{aligned}
$$

The first component in (5) represents the welfare in areas with two competing fiber infrastructures. The second component is the welfare in areas with a single infrastructure and the third term the 
welfare in areas with no fiber infrastructure.

The two first order derivatives of welfare with respect to $a^{O}$ and $a^{N} \operatorname{are}^{22}$

$$
\frac{\partial W}{\partial a^{O}}=\underbrace{\frac{\partial z_{1}^{m}}{\partial a^{O}}}_{(-)} \underbrace{\left(w^{N, O}\left(a^{N}\right)-w^{O, O}\left(a^{O}\right)-c\left(z_{1}^{m}\left(a^{O}, a^{N}\right)\right)\right)}_{(+) \text {or }(-)}+\underbrace{\left(\bar{z}-z_{1}^{m}\right) \frac{d w^{O, O}}{d a^{O}}}_{(-)},
$$

and

$$
\begin{aligned}
& \frac{\partial W}{\partial a^{N}}=\underbrace{\frac{d z_{2}^{c}}{d a^{N}}}_{(+)} \underbrace{\left(w^{N, N}-w^{N, O}\left(a^{N}\right)-c\left(z_{2}^{c}\left(a^{N}\right)\right)\right)}_{(-)}+\underbrace{\frac{\partial z_{1}^{m}}{\partial a^{N}}}_{(+)} \underbrace{\left(w^{N, O}\left(a^{N}\right)-w^{O, O}\left(a^{O}\right)-c\left(z_{1}^{m}\right)\right)}_{(+) \text {or }(-)}(7) \\
& +\underbrace{\left(z_{1}^{m}-z_{2}^{c}\right) \frac{d w^{N, O}}{d a^{N}}}_{(-)}
\end{aligned}
$$

Equation (6) shows that the regulator can set $a^{O}$ to achieve a maximum per-area welfare in uncovered areas (i.e., $a^{O}=0$ ), and then it could set $a^{N}$ to achieve a socially optimal global fiber network coverage (i.e., by choosing $a^{N}$ such that $\left.w^{N, O}\left(a^{N}\right)-w^{O, O}\left(a^{O}\right)-c\left(z_{1}^{m}\right)=0\right){ }^{23}$ That is, the regulator can solve the conflict between static efficiency in uncovered areas and incentives to invest in a monopoly fiber infrastructure. However, as equation (7) clearly shows, by setting such values for $a^{O}$ and $a^{N}$, the regulator will not be able to maximize static efficiency in partially covered areas (the last term of the equation) and to set the right incentives to duplicate an existing fiber infrastructure (the first term in the equation) - or only by chance. Therefore, geographical differentiation of access prices fails to resolve completely the tension between the three regulatory objectives. We can therefore state the following result.

Proposition 2 When the incumbent dominates fiber investments, differentiating the copper access

\footnotetext{
${ }^{22}$ See Appendix $\mathrm{F}$ for the signs of the different terms in (6) and (7).

${ }^{23}$ When $a^{N}$ is very small, $w^{N, O}\left(a^{N}\right)$ is high and $c\left(z_{1}^{m}\right)$ is small as there is little investment. Therefore, $w^{N, O}\left(a^{N}\right)-$ $w^{O, O}\left(a^{O}\right)-c\left(z_{1}^{m}\right)$ is likely to be positive. Conversely, when $a^{N}$ is high, $w^{N, O}\left(a^{N}\right)$ is low and $c\left(z_{1}^{m}\right)$ is high. Therefore, $w^{N, O}\left(a^{N}\right)-w^{O, O}\left(a^{O}\right)-c\left(z_{1}^{m}\right)$ is likely to be negative. Since $w^{N, O}\left(a^{N}\right)-w^{O, O}\left(a^{O}\right)-c\left(z_{1}^{m}\right)$ decreases with $a^{N}$, it is possible to find the $a^{N}$ that makes it equal to zero.
} 
price in areas with competing fiber infrastructures and areas with a single fiber infrastructure is not enough to achieve the social optimum.

Although geographical differentiation of access prices is not a miracle solution, it outperforms uniform access pricing. Equation (6) suggests that the regulator should set a cost oriented access price to copper in areas with no fiber infrastructure (i.e., a zero access price in our setting due to our normalization), and an above-cost access price to copper network in areas with a fiber infrastructure. At the end of Section 4, we provide a numerical example for differentiated access prices, and compare the market outcome with this access scheme to the outcome with alternative access schemes.

\section{Access to fiber}

In many European countries (such as France, Italy, Germany and Spain), access to fiber ducts is mandated and subject to ex ante control. ${ }^{24}$ In this section we therefore introduce access to fiber, and analyze the interplay between the regulation of access to the copper network and to the fiber network. We consider a symmetric regulation, where both the incumbent and the entrant are required to provide access to their fiber networks at a regulated price, $\widetilde{a}^{25}$

On top of the three industry configurations we have listed in our benchmark case, a fourth configuration is now possible:

4. Service-based competition within the fiber network. Both firms use the same fiber network to compete. Depending on the investment decisions, the network can be owned by the incumbent or the entrant, whereby the owner of the network provides access to the other firm at price $\widetilde{a}$.

\footnotetext{
${ }^{24}$ See Cullen International (2012).

${ }^{25}$ Access is required in the areas where a firm holds a monopoly in the NGN. For example, for a given location where the incumbent has NGN coverage, the incumbent is required to provide to access to the entrant only if the entrant has no NGN coverage in that area.
} 
Let $\widetilde{\pi}_{i}^{N, N}(\widetilde{a})$ and $\pi_{j}^{N, N}(\widetilde{a})$ denote firm $i$ 's profit when it provides access to its fiber network to firm $j \neq i$ and firm $j$ 's profit when it leases access to firm $i$ 's fiber network, respectively. We find that $\partial \widetilde{\pi}_{i}^{N, N}(\widetilde{a}) / \partial \widetilde{a} \geq 0$ for $\widetilde{a}$ not too high, and that $\partial \pi_{j}^{N, N}(\widetilde{a}) / \partial \widetilde{a} \leq 0 .{ }^{26}$ In words, provided that the access price of the fiber is not too high, the gross profits of the firm that owns the fiber network increase with the access price, whereas the opposite is true for the firm that acquires access.

We assume that the access price for fiber is low enough so that the firm that invests less in fiber is always willing to switch from copper to fiber at the wholesale level, which we refer to as the "wholesale migration condition". Formally, this is the case if $\widetilde{a} \leq \widetilde{a}_{1}^{\max }=s^{N}-s^{O}$ when the entrant dominates fiber coverage, and if $\widetilde{a} \leq \widetilde{a}_{2}^{\max }(a)=s^{N}-s^{O}+a$ when it is the incumbent that dominates. For the rest of the analysis, we assume that $\widetilde{a} \leq \min \left\{\widetilde{a}_{1}^{\max }, \widetilde{a}_{2}^{\max }(a)\right\}=s^{N}-s^{O}$, that is, the regulated access price to the fiber network is not too high, so that there is always access to a monopoly fiber infrastructure (rather than to the copper infrastructure).

We determine the entrant's and the incumbent's optimal investment decisions in Appendix G2. We now first characterize the socially-optimal access price for fiber as a function of the access price for copper. Then, we discuss how a switch-off of the copper network would affect fiber equilibrium coverage.

\subsection{Socially optimal access price to the fiber network}

We analyze the regulator's choice of the access price for fiber, and the relationship between the socially optimal fiber access price and the access price to copper.

If the incumbent dominates fiber coverage, the equilibrium coverage are $z_{1}^{*}=\widetilde{z}_{1}^{m}(a, \widetilde{a})$ and

\footnotetext{
${ }^{26}$ See Appendix G1.
} 
$z_{2}^{*}=\widetilde{z}_{2}^{c}(\widetilde{a})$. The social welfare is then

$$
W=\widetilde{z}_{2}^{c}(\widetilde{a}) w^{N, N}+\left(\widetilde{z}_{1}^{m}(a, \widetilde{a})-\widetilde{z}_{2}^{c}(\widetilde{a})\right) w^{N, N}(\widetilde{a})+\left(\bar{z}-\widetilde{z}_{1}^{m}(a, \widetilde{a})\right) w^{O, O}(a)-C\left(\widetilde{z}_{1}^{m}\right)-C\left(\widetilde{z}_{2}^{c}\right)
$$

In Appendix G3, we show that in this case there is a positive relationship between the socially optimal $\widetilde{a}$ and the access price of the legacy network, i.e., $d \widetilde{a}^{w} / d a \geq 0$, if $w^{N, N}(\widetilde{a})-w^{O, O}(a)-$ $c\left(\widetilde{z}_{1}^{m}\right) \geq 0 .{ }^{27}$

On the other hand, if the entrant invests in larger fiber coverage than the incumbent, the equilibrium coverage are $z_{1}^{*}=\widetilde{z}_{1}^{c}(\widetilde{a})$ and $z_{2}^{*}=\widetilde{z}_{2}^{m}(a, \widetilde{a})$, and the social welfare is

$$
W=\widetilde{z}_{1}^{c} w^{N, N}+\left(\widetilde{z}_{2}^{m}-\widetilde{z}_{1}^{c}\right) w^{N, N}(\widetilde{a})+\left(\bar{z}-\widetilde{z}_{2}^{m}\right) w^{O, O}(a)-C\left(\widetilde{z}_{1}^{c}\right)-C\left(\widetilde{z}_{2}^{m}\right) .
$$

We find that the relationship between $\widetilde{a}^{w}$ and $a$ can be reversed, that is, we can have $d \widetilde{a}^{w} / d a \leq 0 .{ }^{28}$

The following figure provides an illustration, when $C(z)=k z^{2} / 2, \bar{z}=4, k=0.3, s^{O}=1$ and $s^{N}=1.4$. For low values of the copper access $a$, the incumbent invests more in equilibrium, and we find that the fiber access price increases with $a$. For higher values of $a$ (but lower than 0.35), it is the entrant that invests more, and $\widetilde{a}^{w}$ decreases with $a .^{29}$

\footnotetext{
${ }^{27}$ Note that this result holds if the marginal investment cost is convex, and it does not necessarily hold when the marginal investment cost is concave.

${ }^{28}$ This holds when the marginal investment cost is convex. See Appendix G3 for the formal proofs.

${ }^{29}$ When $a>0.35$, we have a corner (non-interior) equilibrium where the incumbent invests more. In this case, we find that $\widetilde{a}^{w}$ first increases then decreases with $a$.
} 


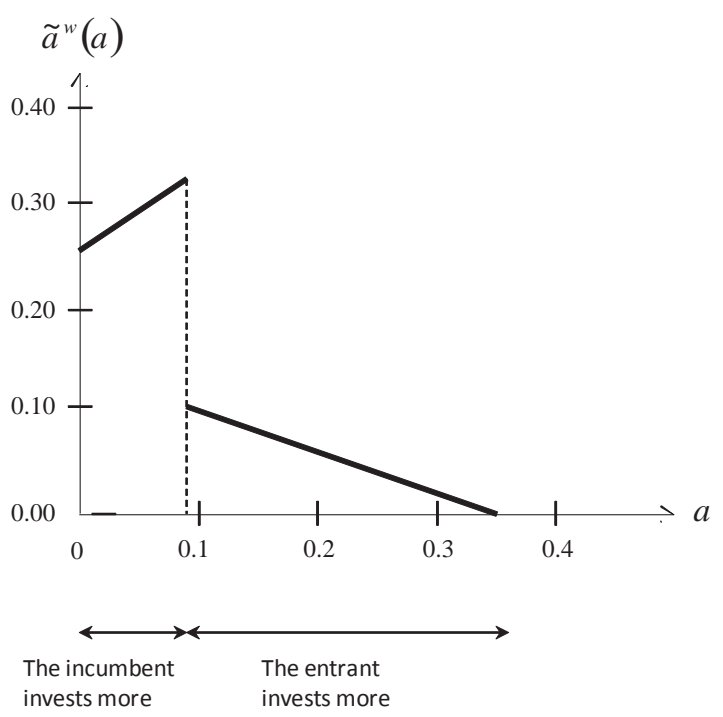

Fig. 1: Socially-optimal fiber access price as a function of the copper access price

The intuition for this difference between the cases when the incumbent or the entrant dominates investment in fiber is as follows. The copper network access price affects the trade-off for the regulator between setting a high fiber access price, which increases marginally fiber coverage, and setting a low fiber network access price, which limits the deadweight loss in the areas with a monopoly fiber infrastructure. How the copper network access price affects the regulator's tradeoff between a low and a high fiber network access price depends on whether it is the incumbent or the entrant that owns the fiber infrastructure subject to access.

When the incumbent owns the monopoly fiber infrastructure, raising the access price to the copper network has three effects, which all gives an incentive to the regulator to increase the fiber access price. First, a higher copper access price reduces the size of the area with a monopoly fiber infrastructure, as it intensifies the wholesale revenue effect, hence reducing the incumbent's investment incentives. This, in turn, reduces the deadweight loss associated to a high fiber access price in the areas with the monopoly fiber network.

Second, a higher copper access price reduces welfare in the areas not covered by a fiber network. Hence, the regulator has an incentive to expand the areas covered with fiber, and to reduce the 
uncovered areas where retail prices tend to increase. Third, the frontier between the uncovered areas and the areas with a monopoly fiber infrastructure becomes more sensitive to the fiber access price; this also gives an incentive to the regulator to increase the fiber access price to encourage investment. All in all, when the incumbent is the "leader" in the deployment of fiber, the socially optimal access price to fiber is positively related to the copper access price.

When the entrant owns the monopoly fiber infrastructure, a higher copper access price increases the entrant's investment incentives because the replacement effect is softened. Since the size of the areas with the monopoly fiber network increases, the regulator has an incentive to lower the fiber access price to reduce the deadweight loss in these areas. At the same time, the marginal gain of rolling out a fiber network in uncovered areas can either increase or decrease, which gives the incentive to the regulator to either increase or decrease the fiber access price.

Finally, the frontier between the uncovered areas and the areas with a monopoly fiber network becomes less sensitive to the fiber access price, which gives an incentive to the regulator to decrease this price. In sum, when the copper access price increases, the regulator should either lower or increase the fiber access price. Hence, the relation between the socially optimal fiber access price and the copper access price can be negative, when the entrant is the "leader" in fiber investments.

Comparing different access schemes. Finally, we analyze how the different access schemes that we have considered in this paper (uniform access price, differentiated access prices, copper and fiber access prices) compare in terms of equilibrium coverage and welfare. The following table gives the equilibrium coverage and welfare for the following parameter values, $\bar{z}=4, k=0.3, s^{O}=1$, and for various values of $s^{N}$ (that satisfy our assumptions). ${ }^{30}$

The table shows that fiber coverage and welfare are lower with a uniform access price than with

\footnotetext{
${ }^{30}$ We obtained similar results with other values for $\bar{z}$. Note that $k$ plays a limited role in these simulations; it is mainly a scaling factor for the equilibrium investments.
} 
a more sophisticated access scheme (differentiated access prices, or access to fiber on top of access to copper). This is because, with a uniform access price, the regulator is very much constrained in setting the uniform access price: it has to be low enough in the areas with an incumbent fiber infrastructure for the entrant to have a positive profit in these areas. The regulator therefore cannot use it to spur investment. This constraint is lifted when there is access price differentiation (either geographical differentiated access prices or fiber access). Having differentiated access prices provides the regulator with greater flexibility in setting the access terms, which increases investment and welfare substantially.

\begin{tabular}{|c|c|c|c|c|}
\hline & & Uniform & Differentiation & Access to fiber \\
\hline \multirow[t]{4}{*}{$s^{N}=1.1$} & Access scheme & $a=0$ & $a^{O}=0.00, a^{N}=0.00$ & $a=0.00, \widetilde{a}=0.06$ \\
\hline & $z_{1}^{*}$ & 0.047 & 0.310 & 0.380 \\
\hline & $z_{2}^{*}$ & 0.044 & 0.296 & 0.180 \\
\hline & $W$ & 7.115 & 7.139 & 7.151 \\
\hline \multirow[t]{4}{*}{$s^{N}=1.2$} & Access scheme & $a=0$ & $a^{O}=0.00, a^{N}=0.03$ & $a=0.00, \widetilde{a}=0.13$ \\
\hline & $z_{1}^{*}$ & 0.098 & 0.590 & 0.800 \\
\hline & $z_{2}^{*}$ & 0.089 & 0.652 & 0.400 \\
\hline & $W$ & 7.129 & 7.228 & 7.278 \\
\hline \multirow[t]{4}{*}{$s^{N}=1.3$} & Access scheme & $a=0$ & $a^{O}=0.00, a^{N}=0.07$ & $a=0.00, \widetilde{a}=0.20$ \\
\hline & $z_{1}^{*}$ & 0.153 & 0.890 & 1.260 \\
\hline & $z_{2}^{*}$ & 0.133 & 1.020 & 0.620 \\
\hline & $W$ & 7.153 & 7.388 & 7.838 \\
\hline
\end{tabular}

In our simulations, the best scenario in terms of global coverage and welfare is with access to fiber. Fiber access turns out to be a more powerful instrument than geographical differentiation of 
access, because the former access scheme operates also when the entrant invests more in fiber than the incumbent.

Finally, note that we cannot have differentiated access prices together with fiber access. When there is access to fiber, there is no access to the copper network in an area where the incumbent has invested in fiber while the entrant has not. In this case, indeed, the entrant uses fiber access rather than copper access (i.e., migration takes place at the wholesale level).

\subsection{Switching off the legacy network}

So far, we have considered that the incumbent can continue to provide access to its copper network, while providing its services over a higher quality fiber network (industry configuration (2.ii)). In some European countries, however, such as Belgium and the Netherlands, there is an on-going debate on whether the incumbents that move from copper to fiber should be imposed to "switch off" their legacy network, i.e., to provide access to their higher quality fiber network only.

In order to study the effect of switching off the copper network, we focus on the candidate equilibrium where the incumbent invests more than the entrant, and has to provide access to its fiber network in the areas where the entrant has not rolled out a fiber network (industry configuration (4) with incumbent's dominance). ${ }^{31}$

In our setting, switching off the copper network has mainly an effect on the wholesale migration condition, which becomes $\pi_{2}^{N, N}(\widetilde{a}) \geq 0$. Due to the switch-off of the copper network, if the entrant does not acquire access to fiber, it earns zero profit. Therefore, as switching off the copper network forces the migration at the wholesale level, the regulator has greater flexibility for setting the fiber access price. However, the rest of our analysis applies, and in particular, the relation between the socially optimal fiber access price and the copper access price remains the same.

\footnotetext{
${ }^{31}$ The switch-off does not occur in the asymmetric equilibrium where the entrant dominates NGN coverage, as the incumbent does not own any monopoly NGN infrastructure in this candidate equilibria.
} 


\section{Conclusion}

This paper studies the effect of access regulation on the incentives to migrate from the legacy (copper) networks to the next generation (fiber) networks. We build on our companion paper (Bourreau et al., 2012) to address new and policy relevant regulatory issues. More specifically, we analyze the effect of three different kinds of regulatory measures: First, geographical access regulation of copper networks - where access prices to copper are differentiated depending on whether or not an alternative fiber network has been deployed; second, access obligations on fiber networks and its interplay with wholesale copper prices; and, finally, a mandatory switch-off of the legacy copper network to foster the transition on the higher quality fiber network.

We show that when setting the access price to the legacy network, the regulator must take into account potential conflicts between investment incentives, static efficiency in uncovered areas, and excessive duplication of infrastructure costs. Introducing different copper network access prices for uncovered areas and partially covered areas (i.e., with a single fiber network), instead of using a simple uniform access regime all over a country, solves some of these conflicts, but not all.

We also point out the effects that emerge when both the old and the new infrastructures are subject to ex ante intervention. Interestingly, our results highlight that regulators cannot treat the access prices to the two different technologies independently. When the incumbent has larger fiber coverage than the entrant, the regulator has to set an access price to the new infrastructure that is positively correlated with the access price to the legacy network. Hence, if the regulator wants to keep the access prices to the copper network relatively low, in order to favor migration at wholesale level (and in turn at the retail level), it also must set a relatively low access price to the fiber network. Whereas the reverse can be true if the entrant has larger fiber coverage than the incumbent: given the relative advantage the incumbent enjoys due to its control over the legacy network, it could be socially optimal for the regulator to set a low access price to the 
copper network to "level" the playing field between the two competitors in the uncovered areas, but also to set a higher access price to the fiber infrastructure controlled by the entrant in order to incentivize investment by both the entrant and the incumbent. This interplay remains unchanged even if the regulator introduces a mandatory switch-off of the copper network to foster migration at the wholesale level.

In policy terms, our result suggests that to the extent that the access price to the legacy network affects investments in fiber by both the incumbent and the entrant, the regulation of access to fiber should be somehow asymmetric, that is, access prices to incumbents' and entrants' fiber networks should be set following different principles, according to the relative market position (in terms of fiber coverage) of each competitor.

An interesting extension of our analysis might be the introduction of competition between ultra-fast networks at both the retail and the wholesale level, due to the presence for example of alternative access technologies such as cable TV, as it happens in some European countries as Belgium and Switzerland. The existence of a technological bypass can affect the way in which a regulator sets access prices to copper and fiber networks. Investors might also be non-profit companies: in several countries, the main investors in NGANs are state-owned companies, in competition or in cooperation with the incumbent operator. This for example happens in Australia, New Zealand and in Italy. The role of state ownership on the migration to ultra-fast broadband networks is relevant per se, but we leave this analysis - as well as the previous one - to future research.

\section{References}

Avenali, A., Matteucci, G., and Reverberi, P. (2010). "Dynamic Access Pricing and Investment in Alternative Infrastructures." International Journal of Industrial Organization, 28(2), 167-175. 
Bourreau, M., and Doğan, P. (2005). "Unbundling the Local Loop." European Economic Review, $49,173-199$.

Bourreau, M., and Doğan, P. (2006). " "Build-or-Buy" Strategies in the Local Loop." American Economic Review, 96, 72-76.

Bourreau, M., Cambini, C. and Doğan, P. (2012). "Access Pricing, Competition, and Incentives to Migrate From "Old" to "New" Technology." International Journal of Industrial Organization, 30(6), 713-723.

Bourreau, M., Cambini, C. and Hoernig, S. (2012a). "Ex ante regulation and co-investment in the transition to next generation access." Telecommunications Policy, 36(5), 399-406.

Bourreau, M., Cambini, C. and Hoernig, S. (2012b). "Geographical Access Rules and Investments." CEPR Discussion Paper No. 9013.

Bourreau, M., Lupi, P. and Manenti, F. (2013). "Old Technology Upgrades, Innovation, and Competition in Vertically Differentiated Markets." Mimeo. http://papers.ssrn.com/ sol3/papers.cfm?abstract_id=2217525

Brito, D., Pereira, P., and J. Vareda (2010). "Can Two-Part Tariffs Promote Efficient Investment on Next Generation Networks?" International Journal of Industrial Organization, 28(3), 323-33.

Brito, D., Pereira, P., and Vareda, J. (2012). "Incentives to Invest and to Give Access to Non Regulated New Technologies." Information Economics and Policy, 24(3-4), 197-211.

Cambini, C., and Jiang, Y. (2009). "Broadband Investment and Regulation. A Literature Review." Telecommunications Policy, 33, 559-574.

Christodoulou, K. and Vlahous, K. (2001). "Implications of Regulation for Entry and Investment in the Local Loop." Telecommunications Policy, 25: 743-757. 
Crandall, R.W., Ingraham, A.T. and Singer, H.J. (2004). "Do Unbundling Policies Discourage CLEC Facilities-Based Investment?" Topics in Economic Analysis and Policy, 4(1), article 14.

Cullen International (2012). Report on NGN deployment and Regulatory issues. April.

Czernich, N., Falck, O., Kretschmer, T. and Woessmann, L. (2011). "Broadband Infrastructure and Economic Growth." The Economic Journal, 121, 505-532.

Distaso, W., Lupi, P. and Manenti, F. (2009). "Static and Dynamic Efficiency in the European Telecommunications Market: The Incentives to Invest and the Ladder of Investment." In Handbook of Research on Telecommunications Planning and Management - (AEBR) Book Series, Vol. 1, Chap. 1, Information Science Reference.

European Commission - DG Info (2012). "Digital Agenda scorecard 2012: Fast and Ultra-Fast Internet Access." June, Brussels.

European Commission (2012). "Draft Recommendation on consistent non-discrimination obligations and costing methodologies to promote competition and enhance the broadband investment environment." December, 7th, Brussels.

Foros, Ø. (2004). "Strategic Investments with Spillovers, Vertical Integration and Foreclosure in the Broadband Access Market." International Journal of Industrial Organization, 22, 1-24.

Gans, J., and Williams, P. (1999). "Access Regulation and the Timing of Infrastructure Investment." The Economic Record, 75(229), 127-137.

Gans, J. (2001). "Regulating Private Infrastructure Investment: Optimal Pricing for Access to Essential Facilities." Journal of Regulatory Economics, 20(2), 167-189.

Gans, J. (2007). "Access Pricing and Infrastructure Investment." In Access Pricing: Theory and Practice, Haucap J. and R. Dewenter (eds.), Elsevier B.V. 
Haydock, J., Langus, G., Lipatov, V., Neven, D., and Shier, G., (2012). "Costing Methodologies and Incentives to Invest in Fibre." Prepared for DG Information Society and Media - European Commission. Charles River Associates, July, London.

Hori, K., and Mizuno, K. (2006). "Access Pricing and Investment with Stochastically Growing Demand." International Journal of Industrial Organization, 24, 705-808.

Hori, K., and Mizuno, K. (2009). "Competition Schemes and Investment in Network Infrastructure." Journal of Regulatory Economics, 35, 179-200.

Katz, M., and Shapiro, C. (1985). "Network Externalities, Competition, and Compatibility." American Economic Review, 75, 424-440.

Kotakorpi, K. (2006). "Access Price Regulation, Investment and Entry in Telecommunications." International Journal of Industrial Organization, 24, 1013-1020.

Inderst, R., and Peitz, M. (2012). "Market Asymmetries and Investments in NGA." Review of Network Economics, 11(1), article 2.

Vareda, J., and Hoernig, S. (2010). "Racing for Investment under Mandatory Access." The BE Journal of Economic Analysis 83 Policy, 10(1), Article 67.

Waverman, L., Meschi, M., Reillier, B. and Dasgupta, K. (2007). "Access Regulation and Infrastructure Investment in the Telecommunications Sector: An Empirical Investigation." LECG Report, available at http://www.etno.be/Portals/34/ETNO\%20Documents/LECG_Final_Report.pdf.

Willig, R. (2006). "Investment is Appropriately Stimulated by TELRIC." Available at: http://psc.ky.gov/pscecf/2003-00379/5200700_efs/04132004/MCI_ST_MTB_EX_14_04\%2013 \%2004.pdf 
WIK (2011). Wholesale Pricing, NGA Take-Up and Competition. Report for ECTA, April, Bad Honnef, Germany.

\section{Appendix}

\section{Appendix A: Per-area profits}

We denote by $s_{1}$ and $s_{2}$ the qualities offered by firm 1 and firm 2, respectively, with $s_{i} \in\left\{s^{O}, s^{N}\right\}$, for $i=1,2$. We provide below the equilibrium per-area profits in the four possible industry configurations.

(1) Service-based competition within the copper network. We have $s_{1}=s_{2}=s^{O}$. The incumbent's profit is $\pi_{1}^{O, O}=p_{1} q_{1}+a q_{2}$, and the entrant's profit is $\pi_{2}^{O, O}=\left(p_{2}-a\right) q_{2}$. In the equilibrium of the quantity-setting game, we have

$$
\pi_{1}^{O, O}(a)=\frac{1}{9}\left(\left(1+s^{O}\right)^{2}+5 a(1-a)+5 a s^{O}\right) \text { and } \pi_{2}^{O, O}(a)=\frac{\left(1+s^{O}-2 a\right)^{2}}{9} .
$$

Note that $\pi_{2}^{O, O}(a) \geq 0$ if and only if $a \leq \bar{a}^{O}=\left(1+s^{O}\right) / 2$. Besides, the incumbent's gross profit is maximized at $\widehat{a}^{O}=\arg \max _{a} \pi_{1}^{O, O}(a)=\left(1+s^{O}\right) / 2=\bar{a}^{O}$.

(2) Infrastructure-based competition between the copper and the fiber networks.

i. The incumbent uses its copper network and the entrant uses its own fiber network. We have $s_{1}=s^{O}$ and $s_{2}=s^{N}$. The incumbent's profit is $\pi_{1}^{O, N}=p_{1} q_{1}$, and the entrant's profit is $\pi_{2}^{O, N}=p_{2} q_{2}$. In equilibrium, we have

$$
\pi_{1}^{O, N}=\frac{\left(1+2 s^{O}-s^{N}\right)^{2}}{9} \text { and } \pi_{2}^{O, N}=\frac{\left(1+2 s^{N}-s^{O}\right)^{2}}{9} .
$$




\section{ii. The incumbent uses a fiber network and the entrant uses the incumbent's copper}

network. We have $s_{1}=s^{N}$ and $s_{2}=s^{O}$. The incumbent's profit is $\pi_{1}^{N, O}=p_{1} q_{1}+a q_{2}$, and the entrant's profit is $\pi_{2}^{N, O}=\left(p_{2}-a\right) q_{2}$. In equilibrium, we have

$$
\pi_{1}^{N, O}(a)=\frac{\left(1+2 s^{N}-s^{O}\right)^{2}+5 a(1-a)+a\left(s^{N}+4 s^{O}\right)}{9} \text { and } \pi_{2}^{N, O}(a)=\frac{\left(1+2 s^{O}-s^{N}-2 a\right)^{2}}{9} .
$$

Note that $\pi_{2}^{N, O}(a) \geq 0$ if and only if $a \leq \bar{a}^{N}=\left(1+2 s^{O}-s^{N}\right) / 2$, and that $\bar{a}^{N}<\bar{a}^{O}$ as $s^{N}>s^{O}$. The incumbent's gross profit is maximized at $\widehat{a}^{N}=\arg \max _{a} \pi_{1}^{N, O}(a)=\left(5+s^{N}+4 s^{O}\right) / 10>\bar{a}^{N}$.

(3) Infrastructure-based competition between the fiber networks. We have $s_{1}=s_{2}=s^{N}$.

The incumbent's profit is $\pi_{1}^{N, N}=p_{1} q_{1}$, and the entrant's profit is $\pi_{2}^{N, N}=p_{2} q_{2}$. In equilibrium, we have

$$
\pi_{1}^{N, N}=\frac{\left(1+s^{N}\right)^{2}}{9} \text { and } \pi_{2}^{N, N}=\frac{\left(1+s^{N}\right)^{2}}{9}
$$

\section{Appendix B: Per-area profit properties}

B1: From the expressions of profits given in Appendix A, we have $\partial \pi_{2}^{k, O}(a) / \partial a \leq 0$, for $k=O, N$. Furthermore, $\pi_{1}^{O, O}(a)$ increases with $a$, for all $a \leq \widehat{a}^{O}=\bar{a}^{O}$. Similarly, $\pi_{1}^{N, O}(a)$ increases with $a$, for all $a \leq \bar{a}^{N}<\widehat{a}^{N}$, as we have $\partial^{2} \pi_{1}^{N, O}(a) / \partial a^{2}<0$ and $\partial \pi_{1}^{N, O}(a) / \partial a\left(a=\bar{a}^{N}\right)=2\left(s^{N}-s^{O}\right) / 3>0$.

B2: First, since $\pi_{1}^{O, O}(a)$ increases with $a$ for $a \leq \widehat{a}^{O}=\bar{a}^{O}$, we have $\pi_{1}^{O, O}(a) \geq \pi_{1}^{O, O}(0)=$ $\left(1+s^{O}\right)^{2} / 9$. Since $s^{O}<s^{N}$, we have $\pi_{1}^{O, N}<\left(1+s^{O}\right)^{2} / 9$, and hence, $\pi_{1}^{O, O}(a)>\pi_{1}^{O, N}$ for all $a$. Second, since $\pi_{1}^{N, O}(a)$ increases with $a$ for all $a \leq \bar{a}^{N}$, we have $\pi_{1}^{N, O}(a) \geq \pi_{1}^{N, O}(0)=$ $\left(1+2 s^{N}-s^{O}\right)^{2} / 9$. As $s^{N}>s^{O}$, we then have $\pi_{1}^{N, O}(a)>\left(1+s^{N}\right)^{2} / 9=\pi_{1}^{N, N}$. 


\section{Appendix C: Proof of Proposition 1}

We study the effect of a higher quality for the copper network, $s^{O}$, on firms' investment in fiber.

We focus on the two asymmetric equilibria, $\left\{z_{2}^{m}, z_{1}^{c}\right\}$ if the entrant dominates in NGN investment, and $\left\{z_{1}^{m}, z_{2}^{c}\right\}$ if it is the incumbent that dominates. We find that $z_{1}^{c}, z_{1}^{m}, z_{2}^{m}$, and $z_{2}^{c}$ decrease with the quality of the copper network, $s^{O}$. Indeed,

$$
\frac{\partial z_{1}^{c}}{\partial s^{O}}=\frac{\partial\left(\pi_{1}^{N, N}-\pi_{1}^{O, N}\right)}{\partial s^{O}}=-\frac{4}{9}\left(1+2 s^{O}-s^{N}\right) \leq 0,
$$

since $s^{N}<1+2 s^{O}$ from our assumptions,

$$
\begin{gathered}
\frac{\partial z_{1}^{m}}{\partial s^{O}}=\frac{\partial\left(\pi_{1}^{N, O}-\pi_{1}^{O, O}\right)}{\partial s^{O}}=-\frac{1}{9}\left(a+4+4 s^{N}\right) \leq 0, \\
\frac{\partial z_{2}^{m}}{\partial s^{O}}=\frac{\partial\left(\pi_{2}^{O, N}-\pi_{2}^{O, O}\right)}{\partial s^{O}}=-\frac{4}{9}\left(1+s^{N}-a\right) \leq 0,
\end{gathered}
$$

as $a \leq \bar{a}^{O}$ and $s^{N}>s^{O}$, and

$$
\frac{\partial z_{2}^{c}}{\partial s^{O}}=\frac{\partial\left(\pi_{2}^{N, N}-\pi_{2}^{N, O}\right)}{\partial s^{O}}=-\frac{4}{9}\left(1+2 s^{O}-s^{N}-2 a\right) \leq 0,
$$

since $a \leq \bar{a}^{N}$.

\section{Appendix D: Social welfare in local areas}

D1: Expressions for social welfare. Recall that $s_{1}$ and $s_{2}$ are the qualities offered by firm 1 and firm 2, respectively. Consumer surplus is given by

$$
C S=\int_{\widetilde{\tau}}^{1}\left(\tau-\widehat{p}^{*}\right) d \tau
$$


where $\widehat{p}^{*}=p_{1}^{*}-s_{1}=p_{2}^{*}-s_{2}$ is the quality-adjusted price in the equilibrium of the quantity-setting subgame, and $\widetilde{\tau}=\widehat{p}^{*}$ is the marginal consumer. We find that $C S=\left(2+s_{1}+s_{2}-a\right)^{2} / 18$. The local social welfare is $w=C S+\pi_{1}+\pi_{2}$, and we find that

$$
w=\frac{\left(4+4 s_{2}+a\right)\left(2+2 s_{2}-a\right)}{18}+\frac{11}{18}\left(s_{1}-s_{2}\right)^{2}+\frac{4}{9}\left(a+1+s_{2}\right)\left(s_{1}-s_{2}\right) .
$$

D2: Variations of local welfare with the copper access price When there is service-based competition within the copper network, we have $s_{1}=s_{2}=s^{O}$, and we find that

$$
\frac{\partial w^{O, O}}{\partial a}=-\frac{a+1+s^{O}}{9}<0
$$

When firm 1 uses a fiber network and firm 2 uses the copper network, we have $s_{1}=s^{N}$ and $s_{2}=s^{O}$, and we find that

$$
\frac{\partial w^{N, O}}{\partial a}=-\frac{a+1+5 s^{O}-4 s^{N}}{9}<0
$$

as $1+5 s^{O}-4 s^{N}>0$ under our assumptions on $s^{N}$.

\section{Appendix E: Equilibrium coverage with differentiated copper access prices}

We begin by determining the entrant's optimal investment decision for a given coverage set by the incumbent, and then we solve for the coverage equilibrium.

The entrant's investment decision. Assume that firm 1 has covered the areas $\left[0, z_{1}\right]$. Firm 2's profit is then given by

$$
\Pi_{2}\left(z_{1}, z_{2}\right)=-C\left(z_{2}\right)+ \begin{cases}z_{2} \pi_{2}^{N, N}+\left(z_{1}-z_{2}\right) \pi_{2}^{N, O}\left(a^{N}\right)+\left(\bar{z}-z_{1}\right) \pi_{2}^{O, O}\left(a^{O}\right) & \text { if } z_{2} \leq z_{1} \\ z_{1} \pi_{2}^{N, N}+\left(z_{2}-z_{1}\right) \pi_{2}^{O, N}+\left(\bar{z}-z_{2}\right) \pi_{2}^{O, O}\left(a^{O}\right) & \text { if } z_{2}>z_{1}\end{cases}
$$


Similar to Bourreau et al. (2012), we define

$$
z_{2}^{c}\left(a^{N}\right)=(c)^{-1}\left(\pi_{2}^{N, N}-\pi_{2}^{N, O}\left(a^{N}\right)\right), \quad \text { and } \quad z_{2}^{m}\left(a^{O}\right)=(c)^{-1}\left(\pi_{2}^{O, N}-\pi_{2}^{O, O}\left(a^{O}\right)\right)
$$

Note that depending on the values of $a^{O}$ and $a^{N}$ we can have either $z_{2}^{m}\left(a^{O}\right)>z_{2}^{c}\left(a^{N}\right)$ or the opposite. If the entrant has higher incentives to invest in the fiber when the incumbent has not invested in a given area, (i.e., $z_{2}^{m}>z_{2}^{c}$ ) the best-response of the entrant is defined by

$$
z_{2}^{\mathrm{BR}}\left(z_{1}\right)=\left\{\begin{array}{cc}
z_{2}^{m}\left(a^{O}\right) & \text { if } \quad z_{1} \leq \widehat{z}_{1} \\
z_{2}^{c}\left(a^{N}\right) & \text { if } \quad z_{1}>\widehat{z}_{1}
\end{array}\right.
$$

where $\widehat{z}_{1}\left(a^{O}, a^{N}\right) \in\left[z_{2}^{c}, z_{2}^{m}\right]$ is the lowest $z_{1}$ such that $\Pi_{2}\left(z_{1}, z_{2}^{c}\left(a^{N}\right)\right) \geq \Pi_{2}\left(z_{1}, z_{2}^{m}\left(a^{O}\right)\right)$. This case is referred to as "the entrant conquests" in Bourreau et al. (2012).

If the entrant invests only in the areas where the incumbent has already invested, (i.e., $z_{2}^{c} \geq z_{2}^{m}$ ), its best-response is

$$
z_{2}^{\mathrm{BR}}\left(z_{1}\right)=\left\{\begin{array}{ccr}
z_{2}^{m}\left(a^{O}\right) & \text { if } & z_{1} \leq z_{2}^{m} \\
z_{1} & \text { if } & z_{2}^{m}<z_{1} \leq z_{2}^{c} \\
z_{2}^{c}\left(a^{N}\right) & \text { if } & z_{1}>z_{2}^{c}
\end{array} .\right.
$$

This case is referred to as "the entrant follows suit" in Bourreau et al. (2012).

The incumbent's investment decision. The profits of the incumbent in both cases are as follows. When the entrant "conquests" (i.e., $\left.z_{2}^{c}<z_{2}^{m}\right)$, firm 1's profit is given by:

$\Pi_{1}\left(z_{1}, z_{2}^{\mathrm{BR}}\left(z_{1}\right)\right)=-C\left(z_{1}\right)+\left\{\begin{array}{l}z_{1} \pi_{1}^{N, N}+\left(z_{2}^{m}-z_{1}\right) \pi_{1}^{O, N}+\left(\bar{z}-z_{2}^{m}\right) \pi_{1}^{O, O}\left(a^{O}\right) \quad \text { if } z_{1} \in\left[0, \widehat{z}_{1}\right] \\ z_{2}^{c} \pi_{1}^{N, N}+\left(z_{1}-z_{2}^{c}\right) \pi_{1}^{N, O}\left(a^{N}\right)+\left(\bar{z}-z_{1}\right) \pi_{1}^{O, O}\left(a^{O}\right) \quad \text { if } z_{1} \in\left[\widehat{z}_{1}, \bar{z}\right]\end{array}\right.$. 
When the entrant "follows suit" (i.e., $z_{2}^{c} \geq z_{2}^{m}$ ), firm 1's profit is given by

$\Pi_{1}\left(z_{1}, z_{2}^{\mathrm{BR}}\left(z_{1}\right)\right)=-C\left(z_{1}\right)+ \begin{cases}z_{1} \pi_{1}^{N, N}+\left(z_{2}^{m}-z_{1}\right) \pi_{1}^{O, N}+\left(\bar{z}-z_{2}^{m}\right) \pi_{1}^{O, O}\left(a^{O}\right) & \text { if } z_{1} \in\left[0, z_{2}^{m}\right] \\ z_{1} \pi_{1}^{N, N}+\left(\bar{z}-z_{1}\right) \pi_{1}^{O, O}\left(a^{O}\right) & \text { if } z_{1} \in\left[z_{2}^{m}, z_{2}^{c}\right] \\ z_{2}^{c} \pi_{1}^{N, N}+\left(z_{1}-z_{2}^{c}\right) \pi_{1}^{N, O}\left(a^{N}\right)+\left(\bar{z}-z_{1}\right) \pi_{1}^{O, O}\left(a^{O}\right) & \text { if } z_{1} \in\left[z_{2}^{c}, \bar{z}\right]\end{cases}$

Let $z_{1}^{c}=(c)^{-1}\left(\pi_{1}^{N, N}-\pi_{1}^{O, N}\right)$, and $z_{1}^{m}\left(a^{O}, a^{N}\right)=(c)^{-1}\left(\pi_{1}^{N, O}\left(a^{N}\right)-\pi_{1}^{O, O}\left(a^{O}\right)\right)$. When the entrant "conquests" and when it "follows suit", we have the same two potential asymmetric equilibria as in the case with uniform access pricing, and either the incumbent or the entrant dominates the fiber investments. That is, the equilibrium coverage is either $\left\{z_{1}^{m}\left(a^{O}, a^{N}\right), z_{2}^{c}\left(a^{N}\right)\right\}$ or $\left.\left\{z_{1}^{c}, z_{2}^{m}\left(a^{O}\right)\right\}\right) \cdot{ }^{32}$

\section{Appendix F: Sign of first-order derivatives of welfare}

(i) $\partial z_{1}^{m} / \partial a^{O}<0, \partial z_{1}^{m} / \partial a^{N}>0$ and $d z_{2}^{c} / d a^{N}>0$. Since $\pi_{1}^{N, O}\left(a^{N}\right)$ increases with $a^{N}$ and $\pi_{1}^{O, O}\left(a^{O}\right)$ increases with $a^{O}$, we have $\partial z_{1}^{m} / \partial a^{O}<0$ and $\partial z_{1}^{m} / \partial a^{N}>0$. Since $\pi_{2}^{N, O}\left(a^{N}\right)$ decreases with $a^{N}$, then $d z_{2}^{c} / d a^{N}>0$.

(ii) $w^{N, O}\left(q^{N}\right)-w^{O, O}\left(a^{O}\right)-c\left(z_{1}^{m}\right)$ can be either positive or negative. From the definition of $z_{1}^{m}$, we have $c\left(z_{1}^{m}\right)=\pi_{1}^{N, O}\left(a^{N}\right)-\pi_{1}^{O, O}\left(a^{O}\right)$. We find that

$$
\begin{aligned}
\Delta_{1}\left(a^{O}, a^{N}\right) & =w^{N, O}\left(a^{N}\right)-w^{O, O}\left(a^{O}\right)-\left(\pi_{1}^{N, O}\left(a^{N}\right)-\pi_{1}^{O, O}\left(a^{O}\right)\right) \\
& =\frac{3\left(a^{N}\right)^{2}-3\left(a^{O}\right)^{2}+2 a^{N}\left(s^{N}-3 s^{O}-2\right)+\left(s^{N}-s^{O}\right)^{2}+4 a^{O}\left(1+s^{O}\right)}{6} .
\end{aligned}
$$

\footnotetext{
${ }^{32} \mathrm{As}$ in the baseline model, there is also a corner asymmetric equilibrium. We focus however on the interior equilibria.
} 
We have $\Delta_{1}(a, a)=\left(s^{N}-s^{O}\right)\left(s^{N}-s^{O}+2 a\right) / 6>0$. However, we can have $\Delta_{1}\left(a^{O}, a^{N}\right)<0$ too. For example, assume that $s^{O}=1, s^{N}=1.2$, then $\Delta_{1}(0,0.2)<0$.

(iii) $w^{N, N}-w^{N, O}\left(a^{N}\right)-c\left(z_{2}^{c}\right)<0$. From the definition of $z_{2}^{c}$, we have $c\left(z_{2}^{c}\right)=\pi_{2}^{N, N}$ $\pi_{2}^{N, O}\left(a^{N}\right)$. We find that

$$
w^{N, N}-w^{N, O}\left(a^{N}\right)-\left(\pi_{2}^{N, N}-\pi_{2}^{N, O}\left(a^{N}\right)\right)=\frac{1}{6}\left(3\left(a^{N}\right)^{2}-2 a^{N}\left(1+s^{O}\right)-\left(s^{N}-s^{O}\right)^{2}\right) \equiv \Delta_{2} .
$$

$\Delta_{2}$ is a second-degree polynomial with an inverted bell-shape, and we have $\partial \Delta_{2} /\left.\partial a^{N}\right|_{a^{N}=0}<0$ and $\Delta_{2}\left(a^{N}=0\right)<0$. Besides, we have $\Delta_{2}\left(a^{N}=\bar{a}^{N}\right)<0$. Therefore, $\Delta_{2}<0$ always holds, and hence, $w^{N, N}-w^{N, O}\left(a^{N}\right)-c\left(z_{2}^{c}\right)<0$.

\section{Appendix G: Access to fiber}

G1: Profits with access to fiber. When one firm (firm 1 or firm 2) leases access to the fiber network of its rival, both firms offer services of quality $s^{N}$. Let firm $i$ be the access provider, and firm $j \neq i$ be the access seeker, with $i, j=1,2$. In the equilibrium of the quantity-setting game, we find that

$$
\tilde{\pi}_{i}^{N, N}(\widetilde{a})=\frac{\left(1+s^{N}\right)^{2}+5 \widetilde{a}\left(1+s^{N}-\widetilde{a}\right)}{9}, \quad \text { and } \quad \pi_{j}^{N, N}(\widetilde{a})=\frac{\left(1+s^{N}-2 \widetilde{a}\right)^{2}}{9}
$$

Firm $j$ has a positive demand if $\widetilde{a} \leq\left(1+s^{N}\right) / 2$. We find that $\partial \widetilde{\pi}_{i}^{N, N}(\widetilde{a}) / \partial \widetilde{a} \geq 0$ for $\widetilde{a} \leq\left(1+s^{N}\right) / 2$, and that $\partial \pi_{j}^{N, N}(\widetilde{a}) / \partial \widetilde{a} \leq 0$.

G2: Equilibrium of the coverage game. We determine the equilibrium of the coverage game when there is access to fiber. We start by determining the entrant's optimal coverage decision, and then solve for the equilibrium. 
The entrant's investment decision. Given firm 1's coverage $z_{1}$, firm 2's profit is

$$
\widetilde{\Pi}_{2}\left(z_{1}, z_{2}\right)=\left\{\begin{array}{l}
z_{2} \pi_{2}^{N, N}+\left(z_{1}-z_{2}\right) \pi_{2}^{N, N}(\widetilde{a})+\left(\bar{z}-z_{1}\right) \pi_{2}^{O, O}(a)-C\left(z_{2}\right) \quad \text { if } z_{2} \leq z_{1} \\
z_{1} \pi_{2}^{N, N}+\left(z_{2}-z_{1}\right) \widetilde{\pi}_{2}^{N, N}(\widetilde{a})+\left(\bar{z}-z_{2}\right) \pi_{2}^{O, O}(a)-C\left(z_{2}\right) \quad \text { if } \quad z_{2}>z_{1}
\end{array}\right.
$$

We define $\widetilde{z}_{2}^{c}$ and $\widetilde{z}_{2}^{m}$ as the values of $z_{2}$ that maximize the first and second lines of $\widetilde{\Pi}_{2}\left(z_{1}, z_{2}\right)$, respectively, for $z_{2} \in[0, \bar{z}]$. We have $\widetilde{z}_{2}^{c}(\widetilde{a})=(c)^{-1}\left(\pi_{2}^{N, N}-\pi_{2}^{N, N}(\widetilde{a})\right)$ and $\widetilde{z}_{2}^{m}(a, \widetilde{a})=(c)^{-1}\left(\widetilde{\pi}_{2}^{N, N}(\widetilde{a})-\right.$ $\left.\pi_{2}^{O, O}(a)\right)$

Since the wholesale migration condition holds, we have $\pi_{2}^{N, N}(\widetilde{a}) \geq \pi_{2}^{N, O}(a)$, which implies that $\widetilde{z}_{2}^{c}(\widetilde{a}) \leq z_{2}^{c}(a)$. In other words, introducing an access offer on the monopoly fiber network increases the replacement effect for the entrant, which in turn decreases its investment incentives. Additionally, we have $\widetilde{z}_{2}^{m}(a, \widetilde{a}) \leq z_{2}^{m}(a)$ as $\widetilde{\pi}_{2}^{N, N}(\widetilde{a}) \leq \pi_{2}^{O, N}$ for all $\widetilde{a} \leq \widetilde{a}_{1}^{\max }$. Finally, we have $\partial \widetilde{z}_{2}^{c} / \partial \widetilde{a}, \partial \widetilde{z}_{2}^{m} / \partial \widetilde{a}, \partial \widetilde{z}_{2}^{m} / \partial a \geq 0$. That is, increasing the access price to the copper network or to the fiber network increases fiber coverage. The entrant's best-response function is then

$$
\widetilde{z}_{2}^{\mathrm{BR}}\left(z_{1}\right)=\left\{\begin{array}{ccr}
\widetilde{z}_{2}^{m} & \text { if } & z_{1} \leq \widetilde{z}_{2}^{m}(a, \widetilde{a}) \\
z_{1} & \text { if } & \widetilde{z}_{2}^{m}(a, \widetilde{a})<z_{1} \leq \widetilde{z}_{2}^{c}(\widetilde{a}) \\
\widetilde{z}_{2}^{c} & \text { if } & z_{1}>\widetilde{z}_{2}^{c}(\widetilde{a})
\end{array} \quad \text { and } \quad \widetilde{z}_{2}^{\mathrm{BR}}\left(z_{1}\right)=\left\{\begin{array}{rrr}
\widetilde{z}_{2}^{m} & \text { if } & z_{1} \leq \widetilde{z}_{1}(a, \widetilde{a}) \\
\widetilde{z}_{2}^{c} & \text { if } & z_{1}>\widetilde{z}_{1}(a, \widetilde{a})
\end{array}\right.\right.
$$

for $\widetilde{z}_{2}^{c}>\widetilde{z}_{2}^{m}$ and $\widetilde{z}_{2}^{c} \leq \widetilde{z}_{2}^{m}$, respectively, where $\widetilde{z}_{1}(a, \widetilde{a})$ is the lowest $z_{1}$ such that $\widetilde{\Pi}_{2}\left(z_{1}, \widetilde{z}_{2}^{c}(\widetilde{a})\right) \geq$ $\widetilde{\Pi}_{2}\left(z_{1}, \widetilde{z}_{2}^{m}(a, \widetilde{a})\right)$ holds. 
The incumbent's investment decision. Consider the case where $\widetilde{z}_{2}^{c}>\widetilde{z}_{2}^{m}$. Firm 1's profit is

$$
\widetilde{\Pi}_{1}\left(z_{1}, \widetilde{z}_{2}^{\mathrm{BR}}\left(z_{1}\right)\right)= \begin{cases}z_{1} \pi_{1}^{N, N}+\left(\widetilde{z}_{2}^{m}-z_{1}\right) \pi_{1}^{N, N}(\widetilde{a})+\left(\bar{z}-\widetilde{z}_{2}^{m}\right) \pi_{1}^{O, O}(a)-C\left(z_{1}\right) & \text { if } z_{1} \in\left[0, \widetilde{z}_{2}^{m}\right] \\ z_{1} \pi_{1}^{N, N}+\left(\bar{z}-z_{1}\right) \pi_{1}^{O, O}(a)-C\left(z_{1}\right) & \text { if } z_{1} \in\left[\widetilde{z}_{2}^{m}, \widetilde{z}_{2}^{c}\right] \\ \widetilde{z}_{2}^{c} \pi_{1}^{N, N}+\left(z_{1}-\widetilde{z}_{2}^{c}\right) \widetilde{\pi}_{1}^{N, N}(\widetilde{a})+\left(\bar{z}-z_{1}\right) \pi_{1}^{O, O}(a)-C\left(z_{1}\right) & \text { if } z_{1} \in\left[\widetilde{z}_{2}^{c}, \bar{z}\right]\end{cases}
$$

Let $\widetilde{z}_{1}^{c}, \widetilde{z}_{1}^{d}$ and $\widetilde{z}_{1}^{m}$ denote the maxima of the first, second, and third lines of $\widetilde{\Pi}_{1}\left(z_{1}, \widetilde{z}_{2}^{\mathrm{BR}}\left(z_{1}\right)\right)$, respectively, for $z_{1} \in[0, \bar{z}]$. Firm 1 's profit can be written in a similar way for $\widetilde{z}_{2}^{c} \leq \widetilde{z}_{2}^{m}$, which yields three maxima for different ranges of values for $z_{1}$.

Note that with the introduction of the fiber access offer, the retail-level migration effect (which is present in determining $z_{1}^{m}$ in the absence of fiber regulation) disappears. Indeed, migration now takes place at the wholesale level, through the entrant's switch to the fiber access offer, which automatically triggers migration at the retail level.

Finally, similar to the baseline setting, we have two potential asymmetric equilibria, one in which the incumbent invests more than the entrant $\left(\left\{\widetilde{z}_{1}^{m}, \widetilde{z}_{2}^{c}\right\}\right)$, and one where it is the entrant that invests more $\left(\left\{\widetilde{z}_{1}^{c}, \widetilde{z}_{2}^{m}\right\}\right)$.

G3: Regulator's choice of the access price to fiber. To begin with, we consider the case where the incumbent invests more than the entrant. The equilibrium coverage are then $z_{1}^{*}=$ $\widetilde{z}_{1}^{m}(a, \widetilde{a})$ and $z_{2}^{*}=\widetilde{z}_{2}^{c}(\widetilde{a})$, and the social welfare is

$$
W=\widetilde{z}_{2}^{c}(\widetilde{a}) w^{N, N}+\left(\widetilde{z}_{1}^{m}(a, \widetilde{a})-\widetilde{z}_{2}^{c}(\widetilde{a})\right) w^{N, N}(\widetilde{a})+\left(\bar{z}-\widetilde{z}_{1}^{m}(a, \widetilde{a})\right) w^{O, O}(a)-C\left(\widetilde{z}_{1}^{m}\right)-C\left(\widetilde{z}_{2}^{c}\right)
$$


Assuming an interior solution, the socially optimal access price to fiber solves

$$
\begin{aligned}
\frac{\partial W}{\partial \widetilde{a}}= & \frac{d \widetilde{z}_{2}^{c}(\widetilde{a})}{d \widetilde{a}}\left(w^{N, N}-w^{N, N}(\widetilde{a})-c\left(\widetilde{z}_{2}^{c}\right)\right)+\frac{\partial \widetilde{z}_{1}^{m}(a, \widetilde{a})}{\partial \widetilde{a}}\left(w^{N, N}(\widetilde{a})-w^{O, O}(a)-c\left(\widetilde{z}_{1}^{m}\right)\right) \\
& +\left(\widetilde{z}_{1}^{m}-\widetilde{z}_{2}^{c}\right) \frac{d w^{N, N}(\widetilde{a})}{d \widetilde{a}} \equiv G(a, \widetilde{a})=0 .
\end{aligned}
$$

Let $\widetilde{a}^{w}$ denote the solution of $G\left(a, \widetilde{a}^{w}\right)=0$. From the implicit function theorem, provided that the second-order condition holds, the sign of $\partial \widetilde{a}^{w} / \partial a$ has the same sign as $\partial^{2} W / \partial \widetilde{a} \partial a$. We find that

$$
\begin{aligned}
\operatorname{sign}\left[\frac{\partial \widetilde{a}^{w}}{\partial a}\right]= & \operatorname{sign}\left[\frac{\partial^{2} W}{\partial \widetilde{a} \partial a}\right]=\operatorname{sign}\left[\frac{\partial^{2} \widetilde{z}_{1}^{m}(a, \widetilde{a})}{\partial \widetilde{a} \partial a}\left(w^{N, N}(\widetilde{a})-w^{O, O}(a)-c\left(\widetilde{z}_{1}^{m}\right)\right)\right. \\
& -\frac{\partial \widetilde{z}_{1}^{m}(a, \widetilde{a})}{\partial \widetilde{a}}\left(\frac{d w^{O, O}(a)}{d a}+\frac{\partial \widetilde{z}_{1}^{m}}{\partial a} c^{\prime}\left(\widetilde{z}_{1}^{m}\right)\right)+ \\
& \left.+\frac{\partial \widetilde{z}_{1}^{m}}{\partial a} \frac{d w^{N, N}(\widetilde{a})}{d \widetilde{a}}\right] .
\end{aligned}
$$

The second term is positive as $\partial \widetilde{z}_{1}^{m} / \partial \widetilde{a} \geq 0, d w^{O, O}(a) / d a \leq 0, \partial \widetilde{z}_{1}^{m} / \partial a \leq 0$ and $c^{\prime}(z) \geq 0$. The third term is also positive as $\partial \widetilde{z}_{1}^{m} / \partial a \leq 0$ and $d w^{N, N}(\widetilde{a}) / d \widetilde{a} \leq 0$. If $w^{N, N}(\widetilde{a})-w^{O, O}(a)-c\left(\widetilde{z}_{1}^{m}\right) \geq 0$, the first term is positive if $\partial^{2} \widetilde{z}_{1}^{m}(a, \widetilde{a}) / \partial \widetilde{a} \partial a \geq 0$. We find that

$$
\frac{\partial^{2} \widetilde{z}_{1}^{m}(a, \widetilde{a})}{\partial \widetilde{a} \partial a}=\frac{\frac{\partial \widetilde{\pi}_{1}^{N, N}}{\partial \widetilde{a}} \frac{\partial \pi_{1}^{O, O}}{\partial a} c^{\prime \prime}\left[(c)^{-1}\left(\widetilde{\pi}_{1}^{N, N}-\pi_{1}^{O, O}\right)\right]}{\left(c^{\prime}\left[(c)^{-1}\left(\tilde{\pi}_{1}^{N, N}-\pi_{1}^{O, O}\right)\right]\right)^{3}} \geq 0
$$

as $\partial \widetilde{\pi}_{1}^{N, N} / \partial \widetilde{a} \geq 0, \partial \pi_{1}^{O, O} / \partial a \geq 0$, and $c^{\prime} \geq 0$, and provided that $c^{\prime \prime} \geq 0$ (i.e., the investment cost is convex). It follows that $\partial \widetilde{a}^{w} / \partial a \geq 0$. Finally, if $w^{N, N}(\widetilde{a})-w^{O, O}(a)-c\left(\widetilde{z}_{1}^{m}\right)<0$, the first term is negative and therefore, the sign of $\partial \widetilde{a}^{w} / \partial a$ is ambiguous.

Now, we consider the case where the entrant invests more than the incumbent; the equilibrium coverage are $z_{1}^{*}=\widetilde{z}_{1}^{c}(\widetilde{a})$ and $z_{2}^{*}=\widetilde{z}_{2}^{m}(a, \widetilde{a})$. The social welfare is

$$
W=\widetilde{z}_{1}^{c} w^{N, N}+\left(\widetilde{z}_{2}^{m}-\widetilde{z}_{1}^{c}\right) w^{N, N}(\widetilde{a})+\left(\bar{z}-\widetilde{z}_{2}^{m}\right) w^{O, O}(a)-C\left(\widetilde{z}_{1}^{c}\right)-C\left(\widetilde{z}_{2}^{m}\right) .
$$


Assuming an interior solution, the socially optimal access price to fiber solves the first-order condition

$$
\begin{aligned}
\frac{\partial W}{\partial \widetilde{a}}= & \frac{d \widetilde{z}_{1}^{c}(\widetilde{a})}{d \widetilde{a}}\left(w^{N, N}-w^{N, N}(\widetilde{a})-c\left(\widetilde{z}_{1}^{c}(\widetilde{a})\right)\right)+\frac{\partial \widetilde{z}_{2}^{m}(a, \widetilde{a})}{\partial \widetilde{a}}\left(w^{N, N}(\widetilde{a})-w^{O, O}(a)-c\left(\widetilde{z}_{2}^{m}\right)\right) \\
& +\left(\widetilde{z}_{2}^{m}-\widetilde{z}_{1}^{c}\right) \frac{d w^{N, N}(\widetilde{a})}{d \widetilde{a}} \equiv H(a, \widetilde{a})=0 .
\end{aligned}
$$

Let $\widetilde{a}^{w}$ denote the solution of $H\left(a, \widetilde{a}^{w}\right)=0$. From the implicit function theorem, provided that the second-order condition holds, the sign of $\partial \widetilde{a}^{w} / \partial a$ has the same sign as $\partial^{2} W / \partial \widetilde{a} \partial a$. We find that

$$
\begin{aligned}
\operatorname{sign}\left[\frac{\partial \widetilde{a}^{w}}{\partial a}\right]= & \operatorname{sign}\left[\frac{\partial^{2} W}{\partial \widetilde{a} \partial a}\right]=\operatorname{sign}\left[\frac{\partial^{2} \widetilde{z}_{2}^{m}(a, \widetilde{a})}{\partial \widetilde{a} \partial a}\left(w^{N, N}(\widetilde{a})-w^{O, O}(a)-c\left(\widetilde{z}_{2}^{m}\right)\right)\right. \\
& -\frac{\partial \widetilde{z}_{2}^{m}(a, \widetilde{a})}{\partial \widetilde{a}}\left(\frac{d w^{O, O}(a)}{d a}+\frac{\partial \widetilde{z}_{2}^{m}}{\partial a} c^{\prime}\left(\widetilde{z}_{2}^{m}\right)\right)+ \\
& \left.+\frac{\partial \widetilde{z}_{2}^{m}}{\partial a} \frac{d w^{N, N}(\widetilde{a})}{d \widetilde{a}}\right] .
\end{aligned}
$$

As $\partial \widetilde{z}_{2}^{m} / \partial \widetilde{a} \geq 0$, the second term is negative if $d w^{O, O}(a) / d a+\partial \widetilde{z}_{2}^{m} / \partial a \times c^{\prime}\left(\widetilde{z}_{2}^{m}\right) \geq 0$, and we assume that this is the case (note that $d w^{O, O}(a) / d a \leq 0$, while $\partial \widetilde{z}_{2}^{m} / \partial a \times c^{\prime}\left(\widetilde{z}_{2}^{m}\right) \geq 0$ ). The third term is always negative as $\partial \widetilde{z}_{2}^{m} / \partial a \geq 0$ and $d w^{N, N}(\widetilde{a}) / d \widetilde{a} \leq 0$. Finally, we find that $w^{N, N}(\widetilde{a})-$ $w^{O, O}(a)-c\left(\widetilde{z}_{2}^{m}\right) \leq 0$, as

$$
\begin{aligned}
w^{N, N}(\widetilde{a})-w^{O, O}(a)-c\left(\widetilde{z}_{2}^{m}\right) & =w^{N, N}(\widetilde{a})-w^{O, O}(a)-\left(\widetilde{\pi}_{2}^{N, N}(\widetilde{a})-\pi_{2}^{O, O}(a)\right) \\
& =\frac{1}{9}[5 \widetilde{a} \underbrace{\left(\widetilde{a}-\left(1+s^{N}\right)\right)}_{(-)}+\underbrace{\left(1+s^{O}-2 a\right)^{2}-\left(1+s^{N}\right)^{2}}_{(-)}] \leq 0 .
\end{aligned}
$$

The first term of $\operatorname{sign}\left[\partial \widetilde{a}^{w} / \partial a\right]$ is then positive as

$$
\frac{\partial^{2} \widetilde{z}_{2}^{m}(a, \widetilde{a})}{\partial \widetilde{a} \partial a}=\frac{\frac{\partial \widetilde{\pi}_{2}^{N, N}}{\partial \widetilde{a}} \frac{\partial \pi_{2}^{O, O}}{\partial a} c^{\prime \prime}\left[(c)^{-1}\left(\widetilde{\pi}_{2}^{N, N}-\pi_{2}^{O, O}\right)\right]}{\left(c^{\prime}\left[(c)^{-1}\left(\widetilde{\pi}_{2}^{N, N}-\pi_{2}^{O, O}\right)\right]\right)^{3}} \leq 0
$$


since $\partial \widetilde{\pi}_{2}^{N, N} / \partial \widetilde{a} \geq 0, \partial \pi_{2}^{O, O} / \partial a \leq 0$, and $c^{\prime} \geq 0$, and provided that $c^{\prime \prime} \geq 0$. Though the sign of $\partial \widetilde{a}^{w} / \partial a$ is ambiguous in general, we can have $\partial \widetilde{a}^{w} / \partial a \leq 0$ when the entrant is the leader in fiber investments in particular when $w^{N, N}(\widetilde{a})-w^{O, O}(a)-c\left(\widetilde{z}_{2}^{m}\right)$ is high enough (provided that $d w^{O, O}(a) / d a+\partial \widetilde{z}_{2}^{m} / \partial a \times c^{\prime}\left(\widetilde{z}_{2}^{m}\right) \geq 0$ and that the investment cost is convex). 
Authors contacts:

\section{Marc Bourreau}

Telecom ParisTech

Department of Economics and Social Sciences

46 rue Barrault

75013 Paris

France

Email: marc.bourreau@telecom-paristech.fr

\section{Carlo Cambini}

Politecnico di Torino

Corso Duca degli Abruzzi, 24

I-10129 Torino

European University Institute

Florence School of Regulation

Via Boccaccio, 151

I-50133 Firenze

Email: carlo.cambini@polito.it

\section{Pınar Doğan}

Harvard Kennedy School of Government

Harvard University

Email: pinar_dogan@hks.harvard.edu 